\title{
Do monitoramento no ambiente de trabalho com a instalação de câmeras
}

\author{
Carlos Junior Silva ${ }^{1}$ \\ Lourival José de Oliveira ${ }^{2}$
}

\section{Resumo}

\begin{abstract}
Analisa a utilização de câmeras como forma de fiscalização das atividades dos empregados no ambiente de trabalho, além de suas funções vitais ligadas a saúde, segurança e proteção. Observa a aplicação dos princípios gerais de monitoração, repudiando o uso indistinto, as "câmeras psicológicas", a violação da intimidade e privacidade. É tolerável desde que os empregados estejam cientes de seu fim e localização e que seja o meio menos intrusivo possível. Sua violação pode ensejar dano moral individual, coletivo e assédio moral. Quanto às gravações, tais podem ser utilizadas como meio de prova, salvo quando não atenderem aos requisitos expostos. Ao final, prioriza a regulamentação de normas para o controle do uso de câmeras e para a busca de um ambiente de trabalho harmonioso, ou seja, produtivo para o empregador e saudável para o empregado. Foi utilizado o método dedutivo com pesquisas bibliográficas em obras de direito e saúde.
\end{abstract}

Palavras-Chave: Ambiente de trabalho; Intimidade e Privacidade; Monitoramento com a instalação de câmeras; Poder diretivo do empregador.

\section{Introdução}

O meio ambiente do trabalho é o elemento essencial para o estudo das relações empregatícias, visto que demonstra a vulnerabilidade do empregado frente ao poder diretivo do empregador. $\mathrm{O}$ ambiente de trabalho deve ser um lugar onde o empregado se sinta confortável, um ambiente amigável, não obstante as cobranças internas inerentes a qualquer empresa.

As relações laborais seguiram os avanços da tecnologia, o implemento de novas técnicas e as mutações econômicas. Assim, é neste contexto que se estuda o monitoramento no ambiente de trabalho com seus desdobramentos nos direitos do empregado e do empregador, diante de uma visão doutrinária, jurisprudencial e legal. 0

Acadêmico do 5ㅇ ano matutino do curso de Direito da Universidade Estadual de Londrina.

Doutor em Direito (PUC-SP); professor adjunto da Universidade Estadual de Londrina; professor da UNOPAR; professor da FACCAR; professor da UNIMAR. 
tema é controvertido pois expõe de maneira execessiva o obreiro, além dos ajustes contratuais.

Nota-se que o poder diretivo do empregador contrapõe-se a subordinção do empregado em todas as suas facetas. Destarte, este como hiposuficiente está mais exposto aos abusos daquele poder. Desse modo, com enfoque na videovigilância e nos limites do poder diretivo, busca-se a criação de critérios sólidos para a utilização das câmeras, atentanto a finalidade social a que devem estar envolvidos tanto os trabalhadores, quanto os empresários no ambiente laboral, com vista a dar cumprimento ao princípio da dignidade da pessoa humana e, ao mesmo tempo, criar um ambiente de trabalho com recursos tecnológicos que atendam as necessidades empresariais.

\section{Conceito de monitoramento e suas modalidades}

O aumento na utilização de altas tecnologias nas empresas é uma realidade inexorável, pois visa tanto a maximização da produção como o controle de todos os atos que envolvem a atividade empresarial. Para Mário Antonio Lobato de Paiva (2002, p. 455), essa revolução é avassaladora e transforma completamente a organização do trabalho. Assim, não há dúvida, que o monitoramento surgiu como mais uma faceta desse contexto.

Monitorar é controlar, supervisionar por diversos meios, fatores ligados à saúde, segurança, meio ambiente, produção, desempenho e outros. O monitoramento pode se manifestar de várias formas no ambiente de trabalho com a utilização de câmeras, rastreamento de sites e e-mails, rastreamento via satélite, escutas telefônicas, revistas pessoais, monitoramento de substâncias prejudiciais à saúde e outros.

\section{Do monitoramento com a instalação de câmeras}

O monitoramento com a utilização de câmeras no ambiente de trabalho é outra forma de manifestação do poder diretivo do empregador. Ele é voltado, em sua essência, para situações ligadas a saúde, segurança pessoal e patrimonial. Entretanto, pode ser encontrado também para a otimização do processo produtivo e controle comportamental dos empregados. 
Alice Monteiro de Barros (2006, p. 569) afirma que o legislador brasileiro não proibiu em nenhum momento a fiscalização e controle por meio de aparelhos audiovisuais, visto ser uma "decorrência lógica do avanço da tecnologia e poderá consistir em um instrumento probatório valioso na avaliação da conduta do empregado".

A videovigilância em estudo deve obedecer a certos princípios gerais que também são comuns a outros tipos de monitoração (e-mail e sites). Tais princípios são encontrados no grupo do artigo 29 da diretiva 95/46 do Conselho da Europa, são eles: necessidade, finalidade, transparência, legitimidade, proporcionalidade, rigor e retenção de dados e, por final, segurança.

NECESSIDADE - o empregador deve verificar se qualquer forma de monitoração é absolutamente necessária para determinado fim. Métodos tradicionais de supervisão, menos intrusivos da privacidade dos indivíduos, devem ser cuidadosamente considerados antes da adoção de qualquer monitoração das comunicações eletrônicas. [...]

FINALIDADE - Os dados devem ser recolhidos para um fim específico, explícito e legítimo, e estes dados não devem ser tratados para qualquer outra finalidade, como monitoração do comportamento do trabalhador;

TRANSPARÊNCIA - O empregador deve abster-se de fazer qualquer monitoração dissimulada do correio eletrônico, exceto em face de lei que PERMITA; [...]

LEGITIMIDADE - O uso dos dados de um trabalhador pelo empregador deve ser feito para fins de interesses legítimos perseguidos por este e não pode violar os direitos fundamentais dos trabalhadores;

PROPORCIONALIDADE - Os dados pessoais abrangidos pela monitoração devem ser adequados, pertinentes e não-excessivos no que se refere ao fim especificado. Este princípio exclui a monitoração geral de cada mensagem de correio eletrônica [sic] e do uso da internet de todo o pessoal, para além do que for necessário para garantir a segurança do sistema. [...] (por exemplo, evitando monitoração automática e contínua);

RIGOR E RETENÇÃO DE DADOS - Quaisquer dados legitimamente guardados não devem ser mantidos para além do tempo que for necessário. Os empregadores devem especificar o período de retenção, não se tendo como normalmente justificado prazo superior a três meses;

SEGURANÇA - O direito de o empregador proteger o sistema contra vírus faz com que a abertura automatizada do correio não seja considera [sic] uma violação do direito do trabalhador à privacidade, DESDE QUE POSTAS EM PRÁTICA SALVAGUARDAS APROPRIADAS (BYRUCHKO JUNIOR , 2006, p. 230-231, grifos do autor).

Com efeito, a monitoração com câmeras deve ser adotada somente nos casos em que for o meio menos intrusivo apto para o fim especificado e legítimo ou pode ser ainda utilizada para comprovar certas ações ou comportamentos, desde que limitadas no espaço e tempo (temporária). Ademais, não podem mirar o comportamento dos trabalhadores e 
muito menos ser uma monitoração geral, devendo ser específica (BYRUCHKO JUNIOR , 2006, p. 224).

O Tribunal Superior do Trabalho, em decisão de agosto de 2006, considerou que a monitoração com a instalação de câmeras para fins de segurança não ofende a intimidade e privacidade dos trabalhadores, estudantes e público em geral, pois visa evitar furtos e roubos. Em outras palavras, está dentro do uso razoável do poder diretivo.

\begin{abstract}
Constata-se que as câmeras de vídeo que instalou em suas dependências (fotografias de fls. 65/70) não estão posicionadas em locais efetivamente reservados à intimidade dos empregados como banheiros, cantinas, refeitórios ou salas de café, nos quais, aí sim, seria inadmissível a prática de fiscalização eletrônica por parte do empregador, sob pena de violação aos referidos direitos fundamentais de seus empregados. Pelo contrário, foram postas em locais onde notoriamente é mais provável a ação de criminosos, como a portaria, a tesouraria ou o estacionamento da instituição de ensino. Além do mais, os documentos de fls. 60/64 comprovam que os obreiros têm ciência da instalação do equipamento audiovisual, de modo que as filmagens não são feitas de modo sorrateiro, evitando, assim, que haja gravação de eventual situação inocente, porém constrangedora aos empregados. (fls. 119) (BRASIL. Tribunal Superior do Trabalho. AIRR no 1830/2003-011-05-40. Relatora: Ministra Maria Cristina Irigoyen Peduzzi, grifo nosso).
\end{abstract}

Vale ressaltar, ainda com base nesse entendimento do referido Tribunal, que não poderá haver monitoração em refeitórios, cantinas, salas de café e banheiros por violarem dispositivos constitucionais fundamentais como a intimidade, vida privada, honra e imagem (art. 5ㅇ, inc. X, CF). Deve-se, ainda, estender por analogia tal posicionamento aos ambientes de repouso e aos destinados aos serviços médicos ou de medicina do trabalho.

Corrobora esse entendimento, o seguinte acórdão do TST, com relação à utilização de câmeras nos banheiros:

AGRAVO DE INSTRUMENTO. RECURSO DE REVISTA. DANO MORAL RECONHECIDO. RATIFICAÇÃO. Nos termos do eg. Regional, revelando-se incontroversa a instalação de equipamentos câmeras de filmagem nas dependências dos banheiros de utilização dos empregados, mais especificamente na porta de entrada dos vasos sanitários e mictórios, tal situação, por si só, gera constrangimento moral e social, caracterizando o dano moral. [...] Diante desta constatação, não se tem dúvida de que a instalação das aludidas câmaras (sic) configura pratica (sic) de ato lesivo desrespeito à dignidade e intimidade do trabalhador que gerou constrangimento moral e social, caracterizando o dano. Basta imaginar que, ao ir ao banheiro, a fim de satisfazer suas necessidades fisiológicas, esteja sendo filmado, para conhecimento do patrão e demais interessados. Ainda que seja admitida a culpa da empresa contratada, não há como afastar a responsabilidade patronal, cuja culpa decorre da negligência de não ter monitorado a prestação de serviço contratado. 0 
ato negligente permitiu a instalação de câmaras (sic) (verdadeiras ou falsas, não importa, porque a conseqüência é a mesma) no ambiente de trabalho do reclamante, provocando, repita-se, constrangimento moral e social, além de ser vexatório.[...] (BRASIL. Tribunal Superior do Trabalho. AIRR no 1926/2003-044-0340.6. 3a T. Relator: Juiz convocado Ricardo Machado. 22 Abr. 2005, grifo nosso).

Quanto às chamadas "câmeras psicológicas", isto é, aquelas desligadas ou falsas, utilizadas apenas para provocar os efeitos que uma normal (ligada) causaria nos empregados, tais devem ser repudiadas em qualquer circunstância. Constituem, na verdade, um artifício ardiloso e covarde que deve agravar o quantum indenizatório. Em consonância, o entendimento da 4a Turma do TST:

Se eventualmente eram 'falsas' tais câmeras (o que não foi provado), o caso se agravaria, a meu ver, porque constituiria um procedimento ardiloso e covarde (veja o depoimento do preposto da reclamada, no processo 01262/2003, fl. 334: 'as câmeras nos banheiros não eram acionadas, sendo apenas câmeras 'psicológicas'; que câmeras psicológicas representam apenas o efeito de que as pessoas estariam sendo observadas' fl. 334). Não se pode ignorar que a empresa visava a intimidação ilegal de seus empregados, quando seu preposto declarou, textualmente, à f. 342 (depoimento colhido no processo 01727-2003): 'que houve contratação para instalação de câmeras reais e psicológicas [...] (BRASIL. Tribunal Superior do Trabalho. AIRR no 78/2004-103-03-40.1. 4a T. Relator: Juiz convocado Luiz Antonio Lazarim. 11 nov. 2005, grifo nosso).

Outro requisito de suma importância atinente à monitoração é a transparência, ou seja, o trabalhador deve ter ciência da monitoração, antes de sua instalação, e para qual fim é utilizado. Aliás, inclusive a localização das mesmas, conforme o preconizado nos seguintes acórdãos dos Tribunais Regionais do Trabalho da 3a Região - MG e da 12a Região - SC, respectivamente:

EMENTA: DANO MORAL - VIOLAÇÃO DA INTIMIDADE DO FUNCIONÁRIO. A instalação de câmera no local de trabalho, com prévia ciência dos empregados, cientes inclusive onde estão, por medida de segurança patrimonial de todos, não ofende o direito à inviolabilidade da intimidade assegurado no inciso $X$ do art. 5o., da Constituição da República (MINAS GERAIS. Tribunal Regional do Trabalho da 3a Região. RO no 01288-2002-106-03-00. 2a T. Relator: Juiz José Maria Caldeira. Pub. 07 maio 2003, grifo nosso).

DANO MORAL. VIOLAÇÃO DA INTIMIDADE. A instalação de câmera filmadora no local de trabalho, sem comunicação prévia aos empregados, ainda que se trate de medida de segurança, ofende o direito à inviolabilidade da intimidade assegurado no inciso $X$ do art. 5o, da Constituição da República, fazendo incidir a norma insculpida no inciso $V$ do aludido dispositivo constitucional ( ${ }^{1}$ SANTA CATARINA. Tribunal Regional do Trabalho da 12a Região. RO no 00825-2001-008-12-00-9. 3a T. Relatora: Juíza Maria de Lourdes Leiria. 26 nov. 2002, grifo nosso). 
Não há dúvida que o princípio constitucional que assegura a intimidade e a privacidade incide nas relações trabalhistas, visto que os próprios princípios da monitoração foram esculpidos para proteger tais bens. Entretanto, não são absolutos, pois por uma interpretação sistemática, o empregador tem a faculdade de estabelecer mecanismos de monitoramento dos empregados para comprovar a produtividade e aplicar sanções de caráter disciplinar (PAIVA, 2002, p. 442-443).

Diante do exposto, não se pode esquivar a pergunta: realmente são lícitos os monitoramentos comportamentais? Alexandre Agra Belmonte (2004, p. 76) entende que a finalidade da vigilância deve ser expressa, não podendo haver desvio. Traz, como exemplo, que "o circuito interno de TV instalado para fins de formação profissional ou treinamento dos empregados" em nenhuma hipótese pode "justificar a aplicação de penalidades disciplinares ou mesmo a dispensa dos empregados". Pelo princípio da finalidade, que veda o monitoramento comportamental, esta tese parece ser a mais razoável.

Apesar da doutrina e da jurisprudência brasileiras fazerem ressalvas apenas aos banheiros, refeitórios e salas de café, o monitoramento comportamental pode existir na avaliação da conduta do empregado (BARROS, 2006, p. 569). Paradoxalmente, tal entendimento parece ser insustentável, salvo nas hipóteses em que se atende a fins legalmente exigidos. Como os utilizados para fins específicos e delimitados no tempo para comprovação de determinadas ações/omissões destinadas a prevenção de crimes (BYRUCHKO JUNIOR, 2006, p. 224).

Caso venha a ser usada a videovigilância para acompanhamento da produtividade e do rendimento, não existindo outro meio menos intrusivo, deve ser utilizada como um procedimento de gestão, nada tendo com os dados pessoais dos trabalhadores. Esse é o argumento mais utilizado pelas empresas que adotam tal procedimento, ressaltando que os dados colhidos estariam direcionados para a prestação do trabalho e não para os trabalhadores (GUERRA apud BYRUCHKO JUNIOR, 2006, p. 229).

Assim, o empregador poderá apenas controlar a produção/ rendimento em face do poder fiscalizatório. Em nenhuma hipótese poderá utilizar o seu poder punitivo para punir condutas que considera desabonadoras da prestação, devido ao princípio da finalidade e sua vinculação. No entanto, em se tratando de relações de trabalho, e diante do poder diretivo do empregador e da subordinação do empregado, a referida monitoração refletirá, sem 
dúvida, no poder diretivo do empregador. Em outras palavras, na pior das situações, a dispensa sem justa causa poderá macular muitos motivos decorrentes da exposição excessiva do empregado frente ao empregador.

Por outro lado, a visualização de grandes planos e até mesmo de focos específicos, pode muitas vezes incidir na violação dos princípios contratuais da confiança mútua, boa-fé, limites econômicos e sociais dos contratos (BYRUCHKO JUNIOR, 2006, p. 224). Consoante Maria Helena Diniz (2004, p. 41), nos contratos "as partes deverão agir com lealdade, honestidade e confiança recíprocas, isto é, proceder com boa fé, esclarecendo os fatos e o conteúdo das cláusulas, procurando equilíbrio nas prestações, evitando o enriquecimento indevido, não divulgando informações sigilosas etc".

Ainda nesta seara, surge a preocupação em manter os dados colhidos. Segundo o princípio do rigor e retenção de dados, é razoável o arquivamento por três meses das imagens gravadas. $\mathrm{O}$ excesso deverá ser justificado. Além disso, os dados não poderão ficar expostos a qualquer funcionário e somente devem ser utilizados na implementação das causas que lhes originaram.

Em suma, a monitoração deve seguir certos princípios para sua humanização. É permitida nos casos de saúde, segurança e proteção; é tolerada nas hipóteses de acompanhamento produtivo, não sendo crível o desvio de sua finalidade, e a comportamental nas situações baseadas em lei (legítimas); é necessária a prévia ciência dos empregados com relação aos seus fins e respectivas localizações; é vedada em locais mais íntimos como refeitórios, banheiros, salas de café, de repouso e médicas. Ademais, quanto aos dados recolhidos devem ter acesso restrito e devem ser examinados apenas com a implementação da causa que Ihes originaram e não podem ser retidos em arquivos por mais de três meses.

\subsection{Legislações comparadas}

Um método útil para facilitar o entendimento das decisões é o comparativo. Possui considerável relevância, seja para exemplificar, seja para fundamentar possíveis lacunas existentes nos ordenamentos.

Neste tópico será analisado o sistema de videovigilância na Itália, Portugal, Canadá, Bélgica e Inglaterra, de forma resumida e despretensiosa de grandes questionamentos. 
Na Itália, o art. 4ㅇ do Estatuto dos Trabalhadores:

[...] impede o controle à distancia e desconhecido dos empregados. Só se permitem aparelhos audiovisuais quando exigidos pela natureza da organização e com prévio acordo com a representação sindical ou, na falta desta, com a comissão interna; na falta de ambos, a decisão cabe à 'Inspetoria do Trabalho' (VIANA, 1996, p. 231).

Nota-se que o ordenamento Italiano veda o monitoramento desconhecido, camuflado e prioriza o acordo ou convenção coletiva. Já no Canadá, esse tipo de fiscalização é mais aceito, sendo permitido em causas justificadas. Um exemplo trazido da jurisprudência canadense "considerou legítima a instalação de câmera de vídeo com o objetivo de surpreender dois empregados que espiavam as empregadas por intermédio de um orifício na parede do vestiário das mulheres" (BARROS, 2006, p. 567).

Enquanto na Bélgica, a vigilância geral e de todos os dados de telecomunicações dos trabalhadores de forma constante viola a dignidade da pessoa humana, na Inglaterra, a monitoração é mais controlada. A legislação inglesa possui um Código de Conduta da Autoridade de Controle que permite a fiscalização da quantidade e qualidade do trabalho produzido pelo empregado. No entanto, espera-se do empregador um nível de confiança com "razoável liberdade" ao empregado "para determinar suas ações sem estar constantemente vigiado ou ter de se explicar". Ademais, vale a pena lembrar que para os ingleses, o controle continuado deve ser evitado e deve visar sobretudo locais de acesso público (BYRUCHKO JUNIOR, 2006, p. 231-232).

Mesmo assim, devem estar presentes normas gerais de controle, as quais se destacam:

[...] estabelecer a finalidade comercial específica para a qual o controle é introduzido; avaliar o impacto do controle na privacidade, autonomia e outros direitos legítimos do pessoal, não introduzindo controles que tenham impacto adverso e desproporcional aos benefícios; ao fazer a avaliação antes referida, consultar os sindicatos e outros representantes dos empregados; ADOTAR MÉTODO COM MENOS IMPACTO ADEVERSO [sic], SE PUDEREM SER ATINGIDOS OS MESMO RESULTADOS; DIRECIONAR O CONTROLE PARA ÁREAS ONDE É, DE FATO, NECESSÁRIO E PROPORCIONAL para atingir a finalidade comercial. O controle de todo o pessoal não se justifica se a finalidade é dirigida a um risco que é colocado apenas por alguns (BYRUCHKO JUNIOR, 2006, p. 231-232). 
Por fim, o sistema português de videovigilância. 0 art. 20 do Código de Trabalho de Portugal traz as seguintes disposições:

1 - O empregador não pode utilizar meios de vigilância a distância no local de trabalho, mediante o emprego de equipamento tecnológico, com a finalidade de controlar o desempenho profissional do trabalhador.

2 - A utilização do equipamento identificado no número anterior é lícita sempre que tenha por finalidade a proteção e segurança de pessoas e bens ou quando particulares exigências inerentes à natureza da actividade o justifiquem.

3 - Nos casos previstos no número anterior o empregador deve informa [sic] o trabalhador sobre a existência e finalidade dos meios de vigilância utilizados (BYRUCHKO JUNIOR, 2006, pp. 236-237).

Do preceito citado, conclui-se que o sistema português não adotou o controle do desempenho do trabalhador. A monitoração comportamental é considerada excessiva e desproporcional, admitindo prova em contrário, sendo violadora dos direitos de confiança mútua que o contrato pressupõe. Excepcionalmente, admite-se no caso do processo de produção (linha de montagem) estar voltado para um tipo de controle supervisionado "à distância com o objetivo exclusivo de permitir a interrupção do processo de produção quando se verificar anomalia ou haja perigo para a segurança do trabalhador" (BYRUCHKO JUNIOR, 2006, p. 237).

Diante dos sistemas citados dos diferentes países, os que mais se aproximam da realidade pela qual passa a jurisprudência brasileira são os ordenamentos da Itália, Canadá e Inglaterra. No entanto, os ingleses demonstram estar um passo a frente, quando se preocupam em fazer estudos do impacto da videovigilância na vida privada dos empregados.

Paradoxalmente, a Bélgica veda a monitoração constante e Portugal o controle do desempenho, salvo nas hipóteses de proteção e segurança, tanto dos bens da empresa, quanto dos empregados ou se for inerente à natureza da atividade. Observa-se que, o modelo luso limitador se amoldaria muito bem ao Brasil, porquanto condiz com o momento vivenciado pelas relações trabalhistas tupiniquins. Com efeito, o monitoramento com a instalação de câmeras não seria usado indistintamente, como ocorre nos dias de hoje. 


\subsection{Da substituição da revista pessoal}

Qualquer tipo de monitoramento utilizado pelo empregador deverá ser utilizado de forma menos intrusiva possível à personalidade do empregado. Destarte, em algumas ocasiões mostra-se mais adequado o uso do monitoramento com câmeras à revista pessoal.

Alice Monteiro de Barros (2006, p. 560) ensina que a revista só se justifica se não houver outro meio preventivo apto para o fim almejado e pode traduzir "um comodismo do empregador para defender seu patrimônio". Aliás, continua ela dizendo com base no pensamento do ilustre Federico Duran Lopez (apud BARROS, 2006, p. 560) que:

Não basta a tutela genérica da propriedade, deverão existir circunstâncias concretas que justifiquem a revista. Mister que haja, na empresa, no estabelecimento ou no setor bens suscetíveis de subtração e ocultação, com valor material, ou que tenham relevância para o funcionamento da atividade empresarial e para a segurança das pessoas.

Com efeito, se a atividade for ligada a substâncias proibidas, assim, preconiza a 2aㅡ Turma do TST, em acórdão publicado em fevereiro de 2004, cujo relator foi o Juiz convocado Samuel Corrêa Leite:

INDENIZAÇ̃̃O POR DANO MORAL REVISTA ÍNTIMA. O Eg. Tribunal de origem emitiu entendimento no sentido de que não há dano moral a ser objeto de indenização resultante de vistoria pessoal (revista) feita em empregado despido, mas levada a efeito de forma respeitosa, por empresa que tem de velar pelos produtos que manipula de natureza farmacêutica, tóxica e psicotrópica.

É de todos sabido que o contrato de trabalho envolve um mínimo de fidúcia entre ambas as partes. Se ao empregador remanesce dúvida sobre a integridade moral do candidato ao emprego deve, então recusar a contratação. Não há como conciliar uma confiança relativa com o contrato de trabalho variável conforme a natureza da atividade da empresa. Se esta a direciona para a manipulação de drogas e substâncias psicotrópicas, deve, naturalmente, tomar as precauções necessárias à segurança, como, por exemplo, a instalação de câmeras, que em nada ofendem a dignidade do trabalhador. Mas não pode, a pretexto disso investirse dos poderes de polícia e submeter seus empregados a situações de extremo constrangimento, com total desprezo do direito do cidadão à preservação de sua intimidade. Não é por menos que tais valores e direitos foram erigidos ao status de objeto de garantia constitucional, o que se verifica do contido nos arts. 1ㅇ, III, 5ㅇ, III, e, sobretudo o art. 50, X, todos da Constituição. Nesses preceitos estão garantidos como direitos fundamentais a dignidade da pessoa, a vedação do tratamento desumano e degradante, assim como a inviolabilidade da intimidade e da honra (BRASIL. Tribunal Superior do Trabalho. RR no 533.779/1999. 2a T. Relator: Juiz convocado Samuel Corrêa Leite. 06 fev. 2004, grifo nosso) 
Nota-se no acórdão que apesar do relator entender que a revista foi feita de forma respeitosa, uma das alternativas mais adequadas para o desenvolvimento da atividade citada pode ser o monitoramento com câmeras, desde que seja o meio menos intrusivo para o empregado.

Enfim, com sabedoria, a Procuradora Geral do Ministério Público do Trabalho Sandra Lia Simon (2004, p. 402-403), condensou o entendimento de Márcio Túlio Viana e Alice Monteiro de barros, sobre as revistas pessoais:

a) a indispensabilidade para a tutela do patrimônio é o requisito que limita a própria realização da revista, pois em havendo outro tipo de controle (entrada e saída de estoque, filmagens através de circuito interno, colocação de etiquetas magnéticas, vigilância feita por serviço especializado, etc) não há justificativa para a realização da mesma; b) deverão existir fatos concretos, como, por exemplo, a existência de 'bens suscetíveis de subtração e ocultação, com valor material, ou que tenham relevância para o funcionamento da atividade empresarial'; c) sendo imprescindível a realização da revista, esta deverá atender aos seguintes requisitos: só pode ser realizada na saída dos locais de trabalho, mediante um sistema de seleção automática e decorrente de acordo entre o empregador e a representação dos trabalhadores. No caso de ser realizada diretamente no corpo do empregado, 'poderá traduzir atentado contra o pudor natural da pessoa, mas dependerá da intensidade do exame. Portanto, considera-se atentatória à intimidade a inspeção a qual exige que o indivíduo se desnude completamente, ainda que perante pessoas do mesmo sexo, e submeta-se a exame minucioso, detalhado, prolongado ou em presença de outros'.

Em suma, a revista íntima deve ser abolida, a não ser em atividades que realmente a justifique e desde que seja utilizada como último recurso eficaz. Desse modo, a utilização de meios alternativos de vigilância como a instalação de câmeras, controle de estoque, utilização de etiquetas magnéticas ou até de detectores de metais, desde que se mostrem mais aptos e menos intrusivos, devem ser analisados, antes de qualquer providência que atente a dignidade dos empregados e, conseqüentemente, a honra e a intimidade dos mesmos.

\section{Limites}

Os limites do monitoramento no ambiente de trabalho já foram tratados parcialmente no item 3 deste artigo, quer quando restringe a videovigilância em certos lugares, quer quando associa os mesmos a proteção à intimidade e privacidade do empregado. Igualmente, quando analisa os princípios adotados na monitoração em geral. 
Neste item, será estudada, com maior ênfase, a incidência dos direitos fundamentais da intimidade e privacidade na ambiência obreira.

\subsection{Do direito à intimidade e à privacidade do empregado versus o poder diretivo do empregador}

O poder diretivo do empregador pode ser dividido didaticamente em poder de organização, poder de controle ou fiscalizatório e poder disciplinar. Maior apreço será destinado ao poder fiscalizatório frente aos direitos do empregado.

Segundo Gustavo Felipe Barbosa Garcia (2007, p. 167), o poder de controle autoriza:

[...] que o empregador gerencie a atividade laboral dos empregados, no que tange à prestação de serviços, no sentido de observarem as diversas regras e ordens por ele e pelo sistema jurídico exigidas. [...] Dessa forma, o empregador pode, dentro dos limites estabelecidos pelo ordenamento jurídico, verificar se os empregados estão respeitando as exigências e diretrizes estabelecidas para o desempenho da atividade laborativa.

Diante das assertivas, vem a recorrente pergunta: até que ponto esse poder pode incidir nos direitos fundamentais do empregado?

Sem dúvida, não há resposta simples para o caso, visto que de um lado está o detentor dos meios de produção e do outro o detentor da mão-de-obra. No entanto, a Constituição Federal assegurou em seu art. 5ㅇ, inc. X, que "são invioláveis, a intimidade, a vida privada, a honra e a imagem das pessoas, assegurado o direito a indenização pelo dano material ou moral decorrente de sua violação".

Os direitos à intimidade e à privacidade são direitos da personalidade, assim como o direito à vida, à liberdade, honra, imagem e à dignidade da pessoa humana. Para Tércio Sampaio Ferraz Júnior (apud SIMON, 2004, p. 407), enquanto a intimidade "é o âmbito do exclusivo que alguém reserva para si, sem nenhuma repercussão social, nem mesmo ao alcance de sua vida privada que, por mais isolada que seja, é sempre um viver entre os outros", a privacidade abrange "situações em que a comunicação é inevitável das quais, em princípio, são excluídos terceiros" (desconhecidos). Continua o autor, ainda dizendo que a principal diferença entre eles é que a intimidade não compreende qualquer forma de 
repercussão na sociedade, já que a vida privada envolve, necessariamente, a comunicação com terceiros, ainda que do círculo muito próximo.

De forma prática, a intimidade "é o domínio do homem sobre o homem" e engloba "os sentimentos, as escolhas, sobretudo sexuais, as crenças, as quais estão, sem dúvida, na raiz do seu comportamento, mas são opções pessoais, das quais só deve justificar à sua consciência". Enfim, ela "é um setor da vida privada, o núcleo mais interno (íntimo) desta" (FERREIRA FILHO, 2003, p. 293).

No tocante a vida privada, tal dá-se sobre "um grupo determinado e escolhido", isto é, "passa no quadro da família, dos amigos" (FERREIRA FILHO, 2003, p. 293). Percebe-se, desse modo, que a privacidade tem caráter mais amplo, sendo a intimidade apenas uma de suas partes.

Nas relações trabalhistas, a incidência desses bens não é diferente. A própria Consolidação das Leis do Trabalho demonstra isso por meio dos arts. 373-A, inc. VI e 483, alínea "e". Com efeito, Alice Monteiro de Barros (2006, p. 631) explica com sabedoria o embate surgido:

Não é o fato de um empregado encontrar-se subordinado ao empregador ou de deter este último o poder diretivo que irá justificar a ineficácia da tutela à intimidade no local de trabalho, do contrário haveria degeneração da subordinação jurídica em um estado de sujeição do empregado.

Consoante Sandra Lia Simón (2004, p. 407), a questão é de colisão de direitos fundamentais. Por um lado encontra-se o poder diretivo do empregador pautado no direito de propriedade e, por outro lado, o direito a inviolabilidade a intimidade e vida privada do empregado. Para Canotilho e Vital Moreira (apud SIMÓN, 2004, p. 402-404), a solução passa por um juízo de ponderação, no qual a principal regra é a da máxima observância e o da mínima restrição. Conseqüentemente, a restrição de um direito só encontrará justificativa na necessidade ou na importância da prevalência do outro direito.

Outros modos de solução apontados por Edílson Pereira de Farias (apud SIMÓN, 2004, p. 404) são:

a) princípio da unidade da constituição, pois os diversos preceitos que compõem o texto constitucional devem ser interpretados como um todo e, não, isoladamente; b) princípio da concordância prática, pois a interpretação dos preceitos 
constitucionais, objetivando efetiva harmonização, deve alcançar a concretização máxima dos direitos envolvidos, e c) princípio da proporcionalidade, a prevalência de um direito em detrimento de outro deve ser a absolutamente necessária para a solução da colisão existente.

Destarte, Gustavo Filipe Barbosa Garcia (2007, p. 170) conclui com precisão e méritos que:

[..] havendo conflito entre o direito de propriedade (do empregador) e os direitos à intimidade e privacidade (do empregado), devem prevalecer estes últimos, pois ligados ao preceito magno de dignidade da pessoa humana, conforme a ponderação dos valores em confronto, exigida pela aplicação do princípio da proporcionalidade. Além disso, a solução aqui defendida está em sintonia com o ideal de máxima observância e mínima restrição dos direitos em conflito.

Portanto, os direitos fundamentais devem ser respeitados na ordem trabalhista e, no máximo, que sejam apenas "modulados na medida do imprescindível do correto desenvolvimento da atividade produtiva" (BARROS, 2006, p. 613).

Por mais que seja um conflito de direitos fundamentais, os direitos à intimidade e privacidade do empregado devem prevalecer sobre o direito de propriedade (ensejador do poder diretivo) do empregador, na medida que este último necessita atingir sua função social (ser mais igualitário). Outrossim, com fulcro no art. 170 da $\mathrm{CF}$, não há dúvida, que a valorização do trabalho humano culmina na proteção da intimidade e privacidade do operário, frente aos avanços tecnológicos.

\section{Do direito a indenização}

\subsection{Do dano moral individual e coletivo e do assédio moral no ambiente de trabalho}

Em face do atributo de subordinação do empregado, o ambiente laboral está propenso a gerar, em maior incidência, o dano moral.

Conforme Francisco Ferreira Jorge Neto e Jouberto de Quadros Pessoa Cavalcante (2004, p. 747), o dano moral ou extrapatrimonial pode ser conceituado como sendo "aquele que se opõe ao dano material, não afetando os bens patrimoniais propriamente ditos, mas atingindo os bens de ordem moral, de foro íntimo da pessoa, como a honra, a liberdade, a intimidade e a imagem". 
A noção de dano moral, sem dúvida, é muito ampla, pois cobre todo o diapasão da personalidade humana, alcançando os ilícitos que causem "desassossego, desconforto, medo, constrangimento, angústia, apreensão, perda da paz interior, sentimento de perseguição ou discriminação, desestabilização pessoal, profissional, social e financeira" (CASTELO apud GONÇALVES, 2003, p. 220). Na verdade, a sua gravidade gira em torno dos valores íntimos da pessoa, base da personalidade de qualquer ser humano por toda a vida.

O dano moral pode ter como agressor tanto o empregado, quando difama o empregador ou a imagem da empresa, quanto o empregador quando denigre a dignidade do empregado (NASCIMENTO, 2005, p. 476).

Quanto ao seu fundamento legal, possui resguardo no CF art. 5ㅇ, caput, incs. V (no qual prevê a indenização) e X (da inviolabilidade dos direitos fundamentais da personalidade). Em outro nível hierárquico, também é encontrado no CC em seu art. 186 e pela CLT nos art. 482, alíneas j, k e art. 483, alínea e.

Pelo já exposto, as revistas abusivas e a instalação de câmeras nos banheiros ou em outros lugares que causem constrangimento ao trabalhador e a sua dignidade ensejam dano moral. Aliás, não apenas o dano moral individual, mas também, o coletivo, por envolver todos os trabalhadores da empresa.

De acordo com a jurisprudência a configuração de dano moral pode afetar grupo ou coletividade:

DANO MORAL COLETIVO. A ocorrência de violação ao direito de intimidade dos empregados configura dano moral coletivo e impõe sua correspondente reparação. Ademais, a filmagem dos trabalhadores durante o período de trabalho, efetivou-se de forma sigilosa, sem ciência dos empregados, configurando agressão ao grupo, prática que afeta negativamente o sentimento coletivo, lesão imaterial que atinge parte da categoria. Inteligência do art. 5o, X, da Carta Magna (BAHIA. Tribunal Regional do Trabalho da 5ạ Região. RO no 02105-2000-016-05. 5a T. Relatora: Juíza Maria Lisboa. 19 jan. 2005, grifo nosso).

Conseqüentemente, como uma especialização do dano moral, o assédio moral é perfeitamente visível nas monitorações excessivas. Consoante Sônia A. C. Mascaro Nascimento (2005, p. 7), o assédio moral configura-se por meio de um abuso psicológico, reiterado, capaz de causar ofensa e com o intuito de deteriorar o ambiente de trabalho, forçando de modo indireto a saída do empregado. 
$\mathrm{O}$ assédio moral pode ser vertical descendente, vertical ascendente e horizontal. $\mathrm{O}$ primeiro se exterioriza por ato praticado pelo superior hierárquico, o segundo, mais raro, quando os subordinados não aceitam a nova chefia e, por último, o terceiro se configura quando praticado por colegas do mesmo grau hierárquico (MINAS GERAIS. Tribunal Regional do Trabalho da 3ạ Região. RO no 00737200610903005. 3a T. Relatora: Juíza Maria Lúcia Cardoso de Magalhães. 10 mar. 2007).

Quanto aos efeitos, tais podem ser diversos, mas afetam, principalmente, à saúde da vítima, podendo até ser considerado doença do trabalho (art. 20 da Lei no 8.213/1991) (BARROS, 2004, p. 361). Igualmente, a empresa também pode sofrer as conseqüências por meio da desídia, erros no serviço e redução na produtividade dos empregados.

Depois das premissas expostas e seus efeitos, a monitoração excessiva e descontrolada parece ser perfeitamente passível de gerar assédio moral.

\footnotetext{
Alguns têm se utilizado desse monitoramento, mas de maneira tão próxima, que acaba por levar o funcionário a um estado de paranóia, levando-o a crer que os diretores da empresa estão vigiando-os por cima dos ombros, prontos para demitilos diante de um mínimo deslize (SOUZA, 2007).
}

A citação acima não parece ser absurda, pois é uma faceta do assédio moral vertical descendente praticado pelo superior hierárquico. A videovigilância permanente e excessiva acarreta, sem dúvida, um dano psicológico e deteriora o meio ambiente do trabalho. A fiscalização por câmeras com focos amplos e gerais para alguns e específicos para outros trabalhadores, pode ser uma forma silenciosa e sutil de assediar, perseguir uma parte dos obreiros, proporcionando um tipo de isolamento que agride o relacionamento no ambiente de trabalho.

\section{Da validade da prova obtida através de câmeras para fisn de demissão por justa causa}

A questão atinente à validade da prova obtida por monitoramento com a utilização de câmeras possui ênfase, devido ao fato do empregador ser detentor dos meios de produção, incidir-lhe responsabilidades e pelo próprio poder diretivo.

Não há dúvida, que é lícito ao empregador controlar as atividades do empregado durante a jornada de trabalho. No entanto, para esse controle e fiscalização deverão ater-se 
aos meios menos intrusivos possíveis à liberdade do empregado, visto que afetam inclusive os direitos da personalidade.

Para o autor português Manoel da Costa Andrade (apud LEÃO; LEÃO, 2002, p. 218) a prova obtida por violação da intimidade da pessoa não deve ser admitida, por haver disposição constitucional (art. 5ㅇ, inc. X, CF). Aliás, a CF no art. 5ㅇ, inc. LVI, proíbe a utilização de provas por meios ilícitos no processo.

Provas ilícitas são aquelas repudiadas pelo direito. A convicção do juiz deve-se dar por meio de provas idôneas, isto é, "provas juridicamente admissíveis" (art. 332 do CPC) (THEODORO JÚNIOR, 2005, p. 389). Em contrapartida, Alexandre Agra Belmonte (2004, p. 98), acredita que "negar a utilização de prova em certos casos significaria negar o direito de comprovar fato tão repudiado pelo direito quanto a transgressão do respeito à intimidade". E continua afirmando que, a melhor solução é utilizar um juízo de valoração/ponderação, "de forma a alcançar o mínimo sacrifício dos direitos envolvidos e obter-se a máxima observância".

No âmbito jurisprudencial admite-se o uso das imagens desde que o empregado esteja ciente da gravação e para que fim é utilizada, conforme segue abaixo:

\begin{abstract}
JUSTA CAUSA. PROVA. GRAVAÇÃO DE IMAGENS. O monitoramento do interior dos veículos da empresa de transporte coletivo por meio de imagens - fato de conhecimento público, pois constante em painéis localizados em ponto de embarque/desembarque - não viola direito do empregado, já que se insere no âmbito do poder diretivo do empregador. Assim, a fita de vídeo contendo imagens do empregado em horário de serviço não pode ser considerada como obtida por meio ilícito e deve ser admitida como prova, ainda mais quando o trabalhador confirma a prática dos atos nela registrados (SANTA CATARINA. Tribunal Regional do Trabalho da 12a Região. RO no 03982-2005-030-12-00-0. 19 T. Relatora: Juiz Garibaldi Tadeu Pereira Ferreira. 09 ago. 2006).
\end{abstract}

Outrossim, pode-se afastar a ilicitude do meio de prova quando o empregado comete delito ou ato grave de improbidade, podendo afetar a imagem da empresa e causando-lhe, inclusive, prejuízos.

Por final, argumenta ainda Alexandre Agra Belmonte (2004, p. 99) que, nestes casos, o empregador poderá invocar a excludente do estado de necessidade (art. 24, caput do Código Penal), somente se diante das circunstâncias, não se poder obter provas por outros meios e não sendo possível exigir do onerado outro tipo de conduta. 
Entretanto, de forma alguma pode haver a captação clandestina de imagens para a formação de provas, inclusive no âmbito administrativo. Neste sentido é o entendimento do TST:

\begin{abstract}
A imagem do obreiro também foi vilipendiada e a prova de tal fato não se resume a confissão presumida. Restou comprovado que o banco reclamado, de forma ilegal, filmou os empregados da agência de Atalaia, inclusive o reclamante, sem a autorização dos obreiros, quando da instrução do processo administrativo. A primeira testemunha apresentada pelo reclamante, Sr. Abelardo, informou, às fs. $683 / 685$, '...que no dia em que prestou esclarecimento, foi filmado depois do depoimento; que quem efetivou a filmagem foi o Auditor de nome EVALDO...'; '...que a filmagem ocorreu no CESEC-Maceió...'; '...que acredita que o autor foi filmado, porque todos os ouvidos foram filmados...'. Atente-se para a firmeza das informações prestadas pela aludida testemunha e para o amadorismo de uma instituição bancária de renome na apuração interna de um ilícito! Restou comprovada, também, a ofensa à honra do reclamante, tanto em sua modalidade subjetiva - sentimento de cada um a respeito de seus atributos morais - como também, em sua modalidade objetiva - aquilo que os outros pensam a respeito do cidadão no tocante a seus atributos intelectuais, morais, etc (BRASIL. Tribunal Superior do Trabalho. AIRR no 569/2000-055-19-00.8. 6a T. Relator: Juiz Convocado Luiz Antonio Lazarim. 10 ago. 2006).
\end{abstract}

Desse modo, as provas obtidas por meio de câmeras são consideradas lícitas, desde que os empregados estejam cientes das gravações e de sua finalidade. Por outro lado, nas hipóteses de ilícitos que, não possuam outro meio mais eficaz para a comprovação dos fatos do que a violação dos direitos fundamentais da intimidade e privacidade, a gravação das imagens deve ser admitida com resguardo, ponderação e proporcionalidade diante do caso concreto.

\title{
7 Conclusão
}

O monitoramento com a instalação de câmeras está inserido nas prerrogativas do poder fiscalizatório do empregador. É permitido nos casos ligados a saúde, segurança e proteção, desde que os empregados estejam cientes da vigilância a que estão expostos, da localização das câmeras e seus fins. Em suma, devem atender aos princípios gerais das monitorações, sendo eles: necessidade, finalidade, transparência, legitimidade, proporcionalidade, rigor e retenção dos dados e segurança. 
Em nenhuma hipótese será tolerada a utilização de câmeras falsas ou "psicológicas", pois se mostram como um artifício covarde, sorrateiro de modo a intimidar os empregados, bem como atenta contra a moral e os bons costumes da sociedade.

A finalidade com que são instaladas as câmeras vincula as partes. Em outras palavras, se forem utilizadas para fins de produtividade, não podem punir condutas, mesmo desabonadoras, que não estejam conectadas ao fim proposto. Desse modo, também são admitidas para fins comportamentais, desde que expresso o motivo.

Com efeito, mesmo sendo defendida pelos empregadores como um procedimento de gestão, sem vinculação dos dados pessoais colhidos, a monitoração pode mascarar a dispensa sem justa causa pela exposição excessiva da vida privada e intimidade do empregado.

Não é crível que o empregador não possua um nível de confiança razoável em seus funcionários a ponto de vigiá-los "24 horas" ou terem de se explicar por qualquer ato. Acima de tudo, o monitoramento deve ser útil e idôneo. Igualmente, não se justifica tal conduta se infringir os princípios contratuais da confiança mútua, boa-fé, limites econômicos e sociais.

Quanto à retenção dos dados, além do limite temporal de três meses de retenção, somente serão analisados com a implementação da condição resolutiva designada e por um número restrito de funcionários responsáveis.

A monitoração não deve ser permitida indistintamente nas empresas. Urge considerar a natureza da organização e a atividade desenvolvida, uma vez que o controle de todo o pessoal não se justifica se a finalidade é dirigida a um risco que é gerado apenas por alguns. Nestes casos, a videovigilância só se justifica quando houver bens suscetíveis de subtração, ocultação, com valor material ou que tenham relevância para o funcionamento da atividade empresarial e para a segurança das pessoas.

O procedimento adotado na Inglaterra, de avaliar o impacto do controle na privacidade dos empregados, é perfeitamente viável no Brasil, sobretudo pela Norma Regulamentadora no 5 e a própria Lei sobre a Política Nacional do Meio Ambiente que possibilita o estudo prévio do impacto ambiental. Entretanto, as normas portuguesas demonstram estar em maior consonância com a situação pela qual o país passa.

Nada impede que a monitoração com câmeras seja implementada em situações que se mostre menos intrusiva do que a revista pessoal. Contudo, anteriormente, deve ser 
estudada a adoção de novas formas alternativas menos gravosas, como o controle de saída e entrada de estoque, colocação de etiquetas magnéticas, detector de metal e outros.

Quando houver choque entre o poder diretivo, baseado no direito de propriedade, e o direito a inviolabilidade da intimidade e privacidade do empregado, deve prevalecer este último, uma vez que o direito de propriedade deve cumprir sua função social. No mesmo diapasão, acrescenta-se a valorização do trabalho humano na ordem econômica e a dignidade da pessoa humana inerente aos direitos invioláveis referidos. Por isso, não faz sentido a monitoração a certos espaços, como refeitórios, cantinas, salas de café, banheiros, locais de repouso e salas destinadas a atendimento médico.

Em casos de restrições, no choque desses direitos fundamentais, deve ser observado o princípio da máxima observância e da mínima restrição, princípio da unidade da Constituição e da proporcionalidade.

Conseqüentemente, a utilização de câmeras de forma abusiva pode ensejar tanto danos morais, quanto assédio moral. Além disso, o dano moral pode ser muitas vezes coletivo quando atingir normas de ordem pública que regem a saúde, segurança, higiene e o meio ambiente do trabalho.

Agora, quanto à produção de provas válidas pela videovigilância, tais são admitidas desde que os empregados estejam cientes de seu fim e dos locais de exposição. Caso contrário, devem ser consideradas provas ilícitas. Por exceção, a utilização das imagens sem a observância desses requisitos, desde que provado que não existe outro meio menos intrusivo e mais eficaz, poderá ser admitida com resguardo, ponderação e proporcionalidade diante do caso concerto.

Portanto, para a busca do meio ambiente de trabalho sadio, urge, desde já, a utilização de meios menos intrusivos possíveis para a fiscalização da prestação laboral. No caso da utilização do monitoramento com câmeras é imperioso o respeito aos direitos fundamentais dos empregados.

Conseqüentemente, frente às novas tecnologias de fiscalização, o uso desenfreado da videovigilância deve ser punido, visto que não pode configurar um comodismo para o empregador. Portanto, é necessária a criação de normas regulamentadoras para estabelecer critérios objetivos para a instalação de câmeras, seja pela organização da atividade, seja pela natureza da atividade desenvolvida, seja pelo tamanho do estabelecimento. Caso contrário, 
a disseminação dessa técnica, nos moldes atuais, poderá violar valores indissociáveis dos seres humanos como a honra, a intimidade e a privacidade.

\section{Referências}

BAHIA. Tribunal Regional do Trabalho da 5a Região. RO no 02105-2000-016-05. 5a T. Relatora: Juíza Maria Lisboa. 19 jan. 2005. Disponível em: <www.trt05.gov.br>. Acesso em: 05 maio 2007.

BARROS, Alice Monteiro de. Assédio moral. COAD Doutrina e Jurisprudência, n. 40, 10 out. 2004.

. Curso de direito do trabalho. 2. ed. São Paulo: LTr, 2006.

BELMONTE, Alexandre Agra. O monitoramento da correspondência eletrônica nas relações de trabalho. São Paulo: LTr, 2004.

BRASIL. Tribunal Superior do Trabalho. AIRR no 1830/2003-011-05-40. Relatora: Ministra Maria Cristina Irigoyen Peduzzi. Disponível em: <www.tst.gov.br>. Acesso em: 05 maio 2007.

. Tribunal Superior do Trabalho. AIRR no 1926/2003-044-03-40.6. 3a T. Relator: Juiz convocado Ricardo Machado. 22 Abr. 2005. Disponível em: <www.tst.gov.br>. Acesso em: 05 maio 2007.

. Tribunal Superior do Trabalho. AIRR no 569/2000-055-19-00.8. 6a T. Relator: Juiz Convocado Luiz Antonio Lazarim. 10 ago. 2006. Disponível em: <www.tst.gov.br>. Acesso em: 20 maio 2007.

. Tribunal Superior do Trabalho. AIRR no 78/2004-103-03-40.1. 4aㅡ. Relator: Juiz convocado Luiz Antonio Lazarim. 11 nov. 2005. Disponível em: <www.tst.gov.br>. Acesso em: 05 maio 2007.

. Tribunal Superior do Trabalho. RR no 533.779/1999. 2a T. Relator: Juiz convocado Samuel Corrêa Leite. 06 fev. 2004. Disponível em: <www.tst.gov.br>. Acesso em: 05 maio 2007.

BYRUCHKO JUNIOR, Viktor. Ação civil pública. Revista do Ministério Público do Trabalho do Rio Grande do Sul/ Procuradoria Regional do Trabalho da 4a Região, n.1 Porto Alegre: PRT4, p. 221-248. dez. 2006.

DINIZ, Maria Helena. Curso de direito civil brasileiro: teoria das obrigações contratuais e extracontratuais. 20. ed. São Paulo: Saraiva, 2004, v.3. 
GARCIA, Gustavo Filipe Barbosa. Curso de direito do trabalho. São Paulo: Método, 2007.

GONÇALVES, Daniel Itokazu. Aspectos relevantes do dano moral trabalhista. COAD Doutrina e Jurisprudência, n. 27, 06 jul. 2003.

JORGE NETO, Francisco Ferreira. CAVALCANTE, Jouberto de Quadros Pessoa. Manual de direito do trabalho. 2. ed. Rio de Janeiro: Lúmen Júris, 2004. v.1.

LEÃO, Jaqueline Miranda.; LEÃO, Marjorie V. C. A legalidade do controle pelas empresas dos e-mails e do uso da sua rede de computadores pelos empregados. COAD Doutrina e Jurisprudência, n. 22, 02 jun. 2002.

MINAS GERAIS. Tribunal Regional do Trabalho da 3a Região. RO no 01288-2002-106-03-00. 2aㅡ T. Relator: Juiz José Maria Caldeira. Pub. 07 maio 2003. Disponível em: <www.mg.trt.gov.br>. Acesso em: 05 maio 2007.

NASCIMENTO, Amauri Mascaro. Curso de direito do trabalho: história e teoria geral do direito do trabalho: relações individuais e coletivas do trabalho. 20. ed. São Paulo: Saraiva, 2005.

NASCIMENTO, Sônia A. C. Mascaro. O assédio moral no ambiente do trabalho (1a Parte). COAD Doutrina e Jurisprudência, n. 01, 12 jan. 2005.

PAIVA, Mário Antonio Lobato de. O monitoramento do correio eletrônico no ambiente de trabalho(*) (1 a Parte). COAD Doutrina e Jurisprudência, n. 43, 2002.

O monitoramento do correio eletrônico no ambiente de trabalho(*) (2 a Parte).

COAD Doutrina e Jurisprudência, n. 44, 03 nov. 2002.

SANTA CATARINA. Tribunal Regional do Trabalho da 12a Região. RO no 00825-2001-008-1200-9. 3a T. Relatora: Juíza Maria de Lourdes Leiria. 26 nov. 2002. Disponível em: <www.trt12.gov.br>. Acesso em: 05 maio 2007.

SANTA CATARINA. Tribunal Regional do Trabalho da 12a Região. RO no 03982-2005-030-1200-0. 1a T. Relatora: Juiz Garibaldi Tadeu Pereira Ferreira. 09 ago. 2006. Disponível em: <www.trt12.gov.br>. Acesso em: 15 maio 2007.

SIMÓN, Sandra Lia. Revistas pessoais: direito do empregador ou desrespeito aos direitos humanos fundamentais do empregado? (1a Parte). COAD Doutrina e Jurisprudência, n. 44, 07 nov. 2004. 
SOUZA, Bruno Soares de. Assédio moral no trabalho. Disponível em:

$<$ http://www.escritorioonline.com/webnews/noticia.php?id_noticia=7141>. Acesso em: 30 maio 2007.

THEODORO JÚNIOR, Humberto. Curso de direito processual civil. Rio de Janeiro: Forense, 2005, v.1.

VIANA, Márcio Túlio. Direito de resistência: possibilidades de autodefesa do empregado em face do empregador. São Paulo: LTr, 1996. 
